\title{
Dental Patient: Human Being or Only A Set of Teeth ??
}

\author{
Aggarwal A1, Srivastava $B^{2}$, Bhatia $\mathrm{HP}^{3}$, Singh AK ${ }^{4}$, Gupta $\mathrm{N}^{5}$
}

\begin{abstract}
The practise of dentistry involves working with patients, who come to us with specific dental problem with a blind faith in us. It is very important that we dentists see our patients as human beings first and not just as a set of teeth. It is rightly said, "Mouth is a Mirror of the Health". Many of the oral diseases are also associated with systemic conditions including stress, diabetes, genetic disorders or age related diseases. Care should be also emphasized on the surrounding environment which equally contributes to the health of the patient.
\end{abstract}

The aim of this article is to create awareness on the human aspect of our patients, to look beyond teeth and the things we can do to care for our patients as a whole and also the environment.

Keywords : Mental health, Positive attitude, Nutrition, Biocompatible materials, environment, psychological health, behaviour and Lifestyle factors.

${ }^{1}$ Professor and Head

Dept. of Public Health Dentistry

Santosh Dental College and Hospital Ghaziabad,

Uttar Pradesh (INDIA)

${ }^{2}$ Professor and Head

Dept. of Pedodontics and Preventive Dentistry

Santosh Dental College \& Hospital Ghaziabad,

Uttar Pradesh (INDIA)

${ }^{3}$ Professor and Head

Dept. of Pedodontics and Preventive Dentistry

Manav Rachna Dental College, Faridabad,

Haryana (INDIA)

${ }^{4}$ Senior Lecturer

Dept. of Pedodontics and Preventive Dentistry

Santosh Dental College \& Hospital Ghaziabad,

Uttar Pradesh (INDIA)

${ }^{5}$ Senior Lecturer

Dept. of Pedodontics and Preventive Dentistry Santosh Dental College \& Hospital Ghaziabad, Uttar Pradesh (INDIA)

\section{Contact Autbor \\ Dr. Archana Aggarwal archanaaggarwal15@gmail.com}

J Oral Health Comm Dent 2014;8(3)166-168

\section{INTRODUCTION}

^ he practise of dentistry involves working with people. Whilst a high degree of technical skill and judgement is required, an understanding of how social and psychological factors impact on oral health is crucial.

The aetiology of many dental diseases, for example dental caries, periodontal disease and oral cancer is greatly influenced by behavioural and lifestyle factors. Furthermore, changes in oral and systemic physiology, induced by psychological state, play an important role in conditions such as functional disorders of the masticatory system and chronic oro-facial pain.

Let us not ignore the impact of dentistry on the environment as well. Let us program ourselves to believe that our patient is not just a set of teeth but a human being and how can we contribute to the overall health of the patients and also the environment we live in.
Believe in creating an environment that is peaceful, safe and gives comfort to the senses. A soothing music during treatment in the clinics has a calming effect on the nerves. Believe in listening to the patient's problems and complains which will give an insight in the present and past dental and medical history. Then address to the primary and secondary concerns. Patient should be made in-charge of their treatment. All treatment options should be explained to the patients. Treatment which may not be available in a given clinic or dental set up should also be informed in the interest of patient and the patients can be referred to a higher centre for the same. Body is one unit and what affects the mouth affects the body and vice versa. Oral health can affect the general health and the overall well being. Dental status predicts and reflects the person's general health. Research states that periodontal disease is a predictor for heart disease. Any sort of infection in the mouth can burden the immune system, can spread to other parts of the body. Oral infection can lead to heart problems, brain abscess and even death. 
Nutrition affects dental health. Research suggests that factors like nutritious diet and healthy lifestyle prevent dental caries and gum diseases. These are also responsible for good health and prevent illness. Research has shown that serious and chronic illness is often associated with dental caries and gum pathologies. For example, poor mental health is associated with dental decay (1-4). It was reported that elderly individuals without dementia were found to have an average of only 2.7 fillings whereas elderly individuals with dementia or Alzheimer's disease averaged 7.8 teeth with fillings (1-4). A recent authoritative review showed a clear association between cavities, gum health and heart disease (5). Connection between diabetes as well as heart disease and dental decay have been associated for decades (6-8). Recent publications concerning periodontal disease and diabetes are listed by AAP. Relation between vitamin $D$ and dental caries have been reported since 1930 (9-20). More than $90 \%$ of these studies concluded that vitamin D supplement prevent cavities in children. Cancer, respiratory ailments, diabetes, heart disease and other ailments are also linked to a vitamin $\mathrm{D}$ deficiency (21). Individuals with low vitamin D levels are reported to have double the risk of dying from heart disease than other causes, was indicated in a study conducted for a period of 8 yrs. Linus Pauling reviewed evidence for vitamin $\mathrm{C}$ (22) and the evidence for niacin (923) was described by Abrahim Hoffer (23) as factors responsible for dental caries.

Individuals with balanced diet and vitamin \& dietary supplements in conjunction with good dental care will have dramatically less cavities and gum problems than individuals who only receive good dental care. Customising the treatment by combining modern dentistry and complimentary therapies like music, massage, meditation etc contribute greatly to a person's mental health, positive attitude and the feel- ing of well being. This will be useful in dealing with stress and anxiety that can lead to rampant caries, MPD syndrome, TMjoint pathologies, apthus ulcers, lichen planus, etc.

Orthodontics can be practiced with a focus on jaw health and cranial balance which will help improve jaw function and comfort. Cosmetic improvement is also achieved, but perhaps more important is to leave the jaw in a healthy position which is balanced with the cranial bones. Best results occur when a team of professionals and patient can all work together to improve total health.

Biocompatible materials favourable for oral cavity, body and the environment should be used. Antibiotics and other medicines should be used sparingly. Chemical mouth washes can be replaced as early as possible with warm saline rinses and water irrigating devices.

Research by prominent scientist have demonstrated that there is release of mercury vapour from silver amalgam restorations which actually intensifies with heat, chewing, grinding and anything acidic within the oral cavity.

Research shows a positive co-relation between brain mercury levels and the number and surfaces of "mercury/ silver" amalgam dental fillings.

Research conducted at the University of Calgary, Faculty of Medicine has demonstrated that trace amounts of mercury can cause the type of damage to nerves, characteristic to Alzheimer's disease. The level of mercury exposure is consistent with those levels found in humans with mercury/silver amalgam dental fillings. The exposure to mercury caused the formation of "neurofibrillar tangles," which are one of the two diagnostic markers for Alzheimer's disease. Scientists also found that other metals, including aluminium, did not cause the damage. "Amyloid plaques" were considered as diagnostic markers in previous research for Alzheimer's disease (24). It has been reported that elderly people without dementia had 2.7 fillings whereas those with dementia or Alzheimer's disease had 7.8 fillings (1).

Once mercury enters the waste stream it is persistent in the environment, entering ground water and waterways. Mercury is absorbed by algae and plankton which is eaten by fish which is subsequently consumed by humans, causes health risk to young and old, pregnant and nursing mothers and those with an impaired ability to detoxify heavy metals. Therefore it is a hazardous waste and must be disposed in accordance with the local laws.

Dr. O'Reilly's in San Diego emphasised environmental impact on dentistry because $14 \%$ of the waste metals in the ocean comes from deadly practices (www.dentistrygoesgreen.com). According to Mr. Dubey, Vice-President of Solmete X Corporation, 20 tonnes of heavy metals released into the environment every year comes from the dental offices in the US. Dr. Suzanne says, "I would like to see solutions implemented for disposables from dentistry and medicine. Waste from packaging and plastic can be generated from just one procedure."

Another hazard in dental setup are radiographs. $\mathrm{X}$ rays are a proven carcinogen. RVG should be preferred over the conventional $\mathrm{x}$ ray films. Its use also avoids the hazardous waste of developer and fixer used in processing the conventional $\mathrm{x}$ - ray films.

The exposure required to obtain optimal image quality was determined using 20 conventional x-ray films (Eastmen, Kodak, Rochester, NY) and radiovisuography (RVG) (Trophy radiology, Vincennes, France). For CCD based intra oral radiographic imaging system, RVG permitted dose reductions $50-65 \%$ for individual exposures in comparison to conventional x-ray film (Ekta x-ray film) and $73-76 \%$ when compared to ultra speed 
films. The dose dynamic for the RVG was 8.6 times narrower than that for conventional film. Perception of low contrast details was not significantly different between either type of $\mathrm{x}$ ray film and RVG (25). A significant reduction in dose combined with ease in radiographic image enhancements such as contrast, stretching and negative to positive, have resulted in the increased use of these imaging systems (25).

\section{CONCLUSION}

Let each one of us contribute in increasing our awareness in these aspects. Let us practise dentistry with consideration to the body as such by understanding the treatment required, using materials which are healthy for the body and the environment, combined with quality care.

\section{REFERENCES}

1. B Ellefsen, P Holm-Pedersen, D E Morse, $M$ Schroll, B Andersen, G Waldemar. Caries Prevalence in Older Persons with and without Dementia. Journal of the American Geriatrics Society 2008;56(1): 59-67.

2. JM Chalmers, KD Carter, AJ Spencer. Caries incidence and increments in community-living older adults with and without dementia. Australian Research Center for Population Oral Health, Dental School, The University of Adelaide, Adelaide, Australia. Gerodontology 2005 19 (2), $80-94$.

3. Friedlander AH, Mahler ME. Major depressive disorder psychopathology, medical management and dental implications. Graduate Medical Education, Veterans Affairs Greater Los Angeles Healthcare System (14), Los Angeles,
CA, USA. Journal of the American Dental Association 2001;132(5):629-38.

4. Stewart R, et al. Oral Health and Cognitive Function in the Third National Health and Nutrition Examination Survey (NHANES III), Psychosomatic Medicine 2008;70:936-41.

5. Meurman JH, Sanz M, Janket S. Oral infection and vascular disease. Institute of Dentistry, University of Helsinki, Finland. Vascular Disease Prevention 2007;4(4): 260-67.

6. Touger-Decker R, Sirois DA, Vernillo AT. Diabetes mellitus: Nutrition and oral health relationships. Department of Primary Care, School of Health-Related Professions, University of Medicine and Dentistry of New Jersey, Newark, NJ, USA. Editor(s): Touger-Decker, Riva. Nutrition and Oral Medicine 2005;185204.

7. Diaz-Romero R, Casanova-Roman R, Beltran-Zuniga $\mathrm{M}$, Belmont-Padilla $\mathrm{J}$, Mendez J, Avila-Rosas H. Oral Infections and Glycemic Control in Pregnant Type 2 Diabetics. Instituto Nacional de Perinatologia, Mexico City, Mex. Archives of Medical Research 2005;36(1):42-48.

8. Twetman S, Johansson I, Birkhed D, Nederfors T. Caries incidence in young type 1 diabetes mellitus patients in relation to metabolic control and cariesassociated risk factors. Caries Research 2002;36(1):31-35.

9. Tisdall FF. The effect of nutrition on the primary teeth. Child Development 1937;8(1):102-04.

10. McBeath EC. Nutrition and diet in relation to preventive dentistry. NYJ Dentistry 1938;8:17-21.

11. McBeath EC, Zucker TF. Role of vitamin $D$ in the control of dental caries in children. Journal of Nutrition 1938;15:547-64.

12. East BR. Nutrition and dental caries. American Journal of Public Health 1938;28:72-76.

13. Mellanby $M$. The role of nutrition as a factor in resistance to dental caries. British Dental Journal 1937;62:241-52.
14. His Majesty's Stationery Office, London. The influence of diet on caries in children's teeth. Report of the Committee for the Investigation of Dental Disease 1936.

15. McBeath FC. Vitamin D studies, 19331934. American Journal of Public Health 1934;24:1028-30.

16. Anderson PG, Williams CHM, Halderson $H$, Summerfeldt $C$, Agnew R. Influence of vitamin $D$ in the prevention of dental caries. Journal of the American Dental Association 1934;21:1349-66.

17. Day CD, Sedwick HJ. Fat-soluble vitamins and dental caries in children. Journal of Nutrition 1934;8:309-28.

18. Agnew MC, Agnew RG, Tisdall FF. The production and prevention of dental caries. Journal of the American Dental Association. JADA 1933;20:193-212.

19. Bennett NG, et al. The influence of diet on caries in children's teeth. Special Report Series - Medical Research Council, UK 1931;159:19.

20. Mellanby M, Pattison CL. The influence of a cereal-free diet rich in vitamin $D$ and calcium on dental caries in children. British Medical Journal 1932;507-10.

21. Brodsky RH, Schick $B$, Vollmer $H$. Prevention of dental caries by massive doses of vitamin D. American Journal of Diseases of Children 1941;62:1183-87.

22. Pauling L. "How to Live Longer and Feel Better." W.H. Freeman and Company, 1986. Revised 2006, Oregon State University Press.

23. Hoffer A, Saul AW. Orthomolecular Medicine for Everyone. Laguna Beach, California, Basic Health Pub, 2008

24. Leong CW, Syed NI, Lorscheider FL. Retrograde Degeneration of Neurite Membrane Structural Integrity of Nerve Growth Cones Following In Vitro Exposure To mercury. Neuro Report 2001;12(4): 733-37.

25. Mamoru Wakoh et al. Radiation exposure with the RGV-S and conventional intraoral $x$ ray film- Oral Radiology 1994;10(1): 33-40. 